\title{
Changing childhood malnutrition in Bangladesh: trends over the last two decades in urban-rural differentials (1993-2012)
}

\author{
Sumon Kumar Das ${ }^{1,2, *}$, Mohammod Jobayer Chisti ${ }^{1}$, Mohammad Abdul Malek ${ }^{1}$, Jui Das ${ }^{1}$, \\ Mohammed Abdus Salam', Tahmeed Ahmed', Abdullah Al Mamun ${ }^{2}$ and Abu Syed \\ Golam Faruque ${ }^{1}$ \\ ${ }^{1}$ Centre for Nutrition and Food Security (CNFS), International Centre for Diarrhoeal Disease Research, Bangladesh \\ (icddr,b), 68 Shaheed Tajuddin Ahmed Sarani, Mohakhali, Dhaka 1212, Bangladesh: ${ }^{2}$ School of Population \\ Health, University of Queensland, Herston Road, Herston, QLD 4006, Australia
}

Submitted 15 January 2014: Final revision received 30 October 2014: Accepted 15 December 2014: First published online 9 February 2015

\begin{abstract}
Objective: The present study determined trends in malnutrition among under-5 children in urban and rural areas of Bangladesh.

Design: Surveillance.

Setting: The study was conducted in the urban Dhaka and the rural Matlab hospitals of the International Centre for Diarrhoeal Disease Research, Bangladesh, where every fiftieth patient and all patients coming from the Health and Demographic Surveillance System were enrolled.

Subjects: A total of 28816 under-5 children were enrolled at Dhaka from 1993 to 2012 and 11533 at Matlab between 2000 and 2012.

Results: In Dhaka, $46 \%$ of the children were underweight, $39 \%$ were stunted and $28 \%$ were wasted. In Matlab, the corresponding figures were $39 \%, 31 \%$ and $26 \%$, respectively. At Dhaka, $0.5 \%$ of the children were overweight and obese when assessed by weight-for-age $Z$-score $>+2 \cdot 00,1 \cdot 4 \%$ by BMI-for-age $Z$-score $>+2 \cdot 00$ and $1.4 \%$ by weight-for-height $Z$-score $>+2.00$; in Matlab the corresponding figures were $0.5 \%, 1.4 \%$ and $1.4 \%$, respectively. In Dhaka, the proportion of underweight, stunting and wasting decreased from $59 \%$ to $28 \%$ (a $53 \%$ reduction), from $54 \%$ to $22 \%$ (59\% reduction) and from $33 \%$ to $21 \%(36 \%$ reduction), respectively, between 1993 and 2012. In Matlab, these indicators decreased from $51 \%$ to $27 \%$ (a $47 \%$ reduction), from $36 \%$ to $25 \%(31 \%$ reduction) and from $34 \%$ to $14 \%$ (59\% reduction), respectively, from 2000 to 2012. On the other hand, the proportion of overweight (as assessed by BMIfor-age $Z$-score) increased significantly over the study period in both Dhaka (from $0.6 \%$ to $2 \cdot 6 \%$ ) and Matlab (from $0.8 \%$ to $2 \cdot 2 \%$ ).

Conclusions: The proportion of malnourished under- 5 children has decreased gradually in both urban and rural Bangladesh; however, the reduction rates are not in line with meeting Millennium Development Goal 1. Trends for increasing childhood obesity have been noted during the study period as well.
\end{abstract}

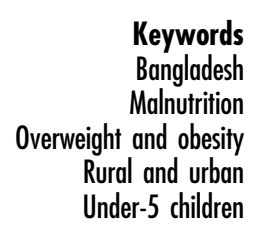

Economic improvement and reduction in poverty, both in developed and developing countries, have been observed within the last couple of decades; however, the pace is not sufficient to meet Millennium Development Goal 1 ('eradicate extreme poverty and hunger') ${ }^{(1)}$. Improvement has also occurred in meeting basic health needs such as the prevention and treatment of infectious and communicable diseases ${ }^{(2)}$, and efforts have been made to ensure provision of safe drinking-water and improved sanitation practices to reduce diarrhoeal episodes ${ }^{(2,3)}$. According to WHO, globally about $27 \%$ of children are stunted ${ }^{(4)}$ and $17 \%$ are underweight ${ }^{(5)}$. The scenario is even worse in the
Asian subcontinent and sub-Saharan Africa ${ }^{(2)}$. Despite efforts to reduce childhood malnutrition through various interventions, it remains a great public health challenge ${ }^{(2)}$.

The other components of malnutrition, such as overweight and obesity, are emerging public health concerns $^{(6,7)}$. In 2011, WHO reported that over 40 million children under the age of 5 years (under-5s) were overweight globally, of whom $75 \%$ were from developing countries $^{(8)}$. Childhood obesity is associated with premature deaths, adulthood disabilities, future respiratory problems, fractures, hypertension, CVD, insulin resistance and psychological disharmony ${ }^{(8)}$. 
According to the Bangladesh Health and Demographic Survey (BDHS) 2000, the prevalence of underweight, stunting and wasting among under- 5 s was $48 \%$, $45 \%$ and $10 \%$, respectively ${ }^{(9)}$, which decreased to $41 \%$, $43 \%$ and $17 \%$, respectively, in $2007^{(10)}$. However, $39 \%$, $43 \%$ and $14 \%$ of rural children were still underweight, stunted and wasted, compared with $28 \%, 36 \%$ and $16 \%$ of children in urban areas, respectively, as reported by the BDHS 2011 survey $^{(11)}$. These surveys neither reported childhood obesity nor clearly documented the shifting of childhood malnutrition over time. The International Centre for Diarrhoeal Disease Research, Bangladesh (icddr,b) has two diarrhoeal disease treatment facilities: one in urban Dhaka (Dhaka Hospital) and the other in rural Matlab (Matlab Hospital). These are the largest diarrhoeal disease hospitals in Bangladesh that provide care and treatment to about 140000 and 20000 patients, respectively, each year $^{(12)}$. icddr,b established a Diarrhoeal Disease Surveillance System (DDSS) at the Dhaka Hospital in 1979, and at the Matlab Hospital in 2000, which systematically collects information such as age, sex and sociodemographic status, and clinical characteristics and aetiology of diarrhoea, among presenting patients. While attending children may be representative of children admitted for care anywhere in Bangladesh because there is lack of population diversity and they have almost similar geographical patterns, they are not a random sample from any child population but children who were admitted for care and thus suffered from some illnesses.

Both of these hospitals receive large numbers of diarrheal children, of whom significant numbers (>25\%) are malnourished ${ }^{(13)}$; Dhaka Hospital has a Nutrition Rehabilitation Unit in which severely malnourished children receive protocol-based management and treatment after the acutephase management that includes appropriate feeding of low-cost culturally acceptable foods and treatment for co-morbidities ${ }^{(13)}$. The problem of overweight and obesity among under- 5 children has not been systematically studied or reported from these hospitals; however, DDSS has the needed information on nutritional status of these children that allows analysis of trends over the decades. This paved the way to observe trends in nutritional status among children under 5 years of age in both urban and rural areas of Bangladesh.

\section{Materials and methods}

\section{Study sites, period and data}

The two diarrhoeal disease hospitals of icddr,b are: (i) Dhaka Hospital in urban Dhaka; and (ii) Matlab Hospital in rural Matlab. For the present analysis, we extracted relevant information for all under- 5 children from the electronic database of the DDSS. The study period for Dhaka and Matlab (the DDSS in Matlab was established in 2000) hospitals was 1993 to 2012 and 2000 to 2012, respectively. Under- 5 children were enrolled in the DDSS irrespective of their age, sex, socio-economic status (SES) and severity of disease in both hospitals.

\section{Diarrboeal Disease Surveillance System}

The DDSS of icddr,b in Dhaka systematically sampled $4 \%$ of all patients from 1979 through 1995, and since 1996 samples $2 \%$ of the patients. The adjusted sample size was based on an increased number of patients (more than double) assuming no major changes in the prevalence of different aetiologies of diarrhoea, which enabled the system to invest money for the detection of additional pathogens of interest. In Matlab, all patients with diarrhoea who resided in the Health and Demographic Surveillance System (HDSS) area and attended Matlab Hospital were enrolled since 2000. The DDSS collects information on the patients' clinical, epidemiological and demographic characteristics and use of drug and fluid therapy at home by administering a structured questionnaire with the assistance of trained research assistants.

\section{Ethics}

At the time of enrolment, verbal consent was taken from the parents or the attending caregivers of each child. icddr,b's DDSS is a routine ongoing activity of the Dhaka Hospital and Matlab Hospital, which has the approval of the institutional Research Review Committee and Ethical Review Committee based on 'no more than minimal risk' to the participants, the voluntary participation and the maintenance of the rights, privacy and confidentiality of the participants.

\section{Assessment of nutritional status}

Anthropometric measurements of the children (weight and length/height) were recorded. Weight was measured to the nearest $100 \mathrm{~g}$ using a digital scale and length/height was measured using a locally constructed length board with a precision of $0 \cdot 1 \mathrm{~cm}$. All anthropometric measurements were performed by trained and experienced research assistants following standard procedures ${ }^{(14)}$. All measurements were subsequently compared with the WHO 2006 growth standards and nutritional status was assessed by $Z$-scores.

\section{Definitions}

The definitions of malnutrition, severe malnutrition, overweight and obese used, which are based on the WHO guidelines $^{(14)}$, are outlined in Table 1.

\section{Data analysis}

Data were analysed using the statistical software packages SPSS for Windows version $15 \cdot 2$ and Epi Info version 6.0. We performed the $\chi^{2}$ test for trend to test for statistical significance in changing trends. Overall and site-specific sociodemographic differences were assessed. Percentage reduction was calculated by subtracting the first 
Table 1 Definitions used in the present study

\begin{tabular}{|c|c|c|}
\hline Condition $^{(4-6,14)}$ & Cut-off (malnutrition) & $\begin{array}{r}\text { Cut-off (severe } \\
\text { malnutrition) }\end{array}$ \\
\hline Underweight & WAZ $<-2.00$ & WAZ $<-3.00$ \\
\hline Stunting & $\mathrm{HAZ}<-2.00$ & $\mathrm{HAZ}<-3.00$ \\
\hline Wasting & $W H Z<-2.00$ & WHZ $<-3.00$ \\
\hline \multirow[t]{3}{*}{ Overweight and obese } & WAZ $>+2.00$ & \\
\hline & $W H Z>+2.00$ & \\
\hline & $\mathrm{BAZ}>+2 \cdot 00$ & \\
\hline Well-nourished & $W A Z, H A Z$ and $W H Z \geq-2.00$ to $\leq+2.00$ & \\
\hline Illiteracy & Having no formal schooling & \\
\hline Income & $\begin{array}{l}\text { Cumulative monthly income of household head (father) and also mother; this was } \\
\text { converted into } \$ \text { US by dividing the monthly income by year-specific conversion rate } \\
\text { of } \$ \text { US }\end{array}$ & \\
\hline Slum area & $\begin{array}{l}\text { An area of the city characterized by dirty, substandard housing condition with a gross } \\
\text { lack of water and sanitation, where dwellers most often share toilets and sources of } \\
\text { drinking-water in large numbers }\end{array}$ & \\
\hline
\end{tabular}

WAZ, weight-for-age Z-score; HAZ, height-for-age Z-score; WHZ, weight-for-height Z-score; BAZ, BMI-for-age Z-score.

observation point from last one, divided by the first observation point and multiplied by 100. Logistic regression analyses were performed for all indicators of undernutrition separately for urban and rural areas at different time points assuming that there might be substantial changes of the predictors of undernutrition over the period. Analysis was done at every 10-year interval, which was considered to be an ideal approach instead of yearwise observations owing to the assumption that a 10 -year interval would be sufficient to evaluate any potential changes. Thus, determinants of undernutrition were assessed in 1993, 2002 and 2012 for Dhaka, and in 2002 and 2012 for Matlab, where a subset of the total sample for each time period was considered separately.

In addition, principal component analysis (factor analysis) was performed to determine wealth quintiles (by using household assets) for each time point separately for each site, assuming that factor loadings for certain household assets may vary through the years, in ascertaining the overall trend and association with malnutrition at different points of observation. Variables included were: construction material of the wall, roof and floor of the house; and household assets (radio, television, cell phone, table, cupboard, local motorized vehicle, animal-drawn cart, refrigerator, motor boat, rickshaw and sanitary toilet). The wealth index was used as a measure of SES using information on household possessions. A weight was attached to each item from the first principal component. The households were classified into quintiles of SES based on the wealth index: quintile $1=$ poor, $2=$ lower middle, $3=$ middle, $4=$ upper middle and quintile $5=$ rich. Moreover, annual inflation rate of \$US was used to estimate the monthly family income.

\section{Results}

A total of 28816 under-5 children were enrolled in the DDSS of urban Dhaka Hospital during 1993-2012.
Of them, 13210 (46\%) were underweight, 11197 (39\%) were stunted and 8031 (28\%) were wasted. Among 11533 under-5 children in rural Matlab, 4505 (40\%) were underweight, 3606 (31\%) were stunted and 2975 (26\%) were wasted during 2000-2012. In Dhaka, 6277 (22\%) were severely underweight, 5125 (18\%) were severely stunted and 2839 (10\%) were severely wasted. In Matlab, the corresponding numbers were 1594 (14\%), 1223 (11\%) and 921 (8\%), respectively. In Dhaka, 158 (0.5\%) children fulfilled the criteria for overweight and obese as assessed by weight-for-age $Z$-score (WAZ) >+2.00, 409 ( $1.4 \%$ ) by weight-for-height $Z$-score (WHZ) $>+2 \cdot 00$ and $402(1.4 \%)$ by BMI-for-age $Z$-score $(\mathrm{BAZ})>+2 \cdot 00$; the corresponding numbers for Matlab were fifty-five (0.5\%), $154(1.4 \%)$ and $160(1.4 \%)$, respectively.

In Dhaka, the proportion of underweight, stunted and wasted children decreased from $59 \%, 54 \%$ and $33 \%$, respectively, in 1993 to $28 \%$ (a $53 \%$ reduction), $22 \%$ (59\% reduction) and $21 \%$ (36\% reduction), respectively, in 2012. Similarly, the proportion of severe underweight, severe stunting and severe wasting decreased significantly from $32 \%, 28 \%$ and $13 \%$, respectively, in 1993 to $10 \%$ (a $69 \%$ reduction), $8 \%$ (71\% reduction) and $8 \%(38 \%$ reduction), respectively, in 2012 . In 2000 , the proportions of underweight, stunted and wasted children were $51 \%$, $36 \%$ and $34 \%$, respectively, in Matlab. The corresponding figures were $27 \%, 25 \%$ and $14 \%$, respectively, in 2012 , representing a significant reduction by $47 \%, 31 \%$ and $59 \%$, respectively, from 2000 (Fig. 1). Severe underweight, severe stunting and severe wasting were reduced by $62 \%$ (from $21 \%$ to $8 \%$ ), 33\% (from $12 \%$ to $8 \%$ ) and $67 \%$ (from $12 \%$ to $4 \%$ ), respectively, over the study period in Matlab. In Dhaka, the proportion of overweight and obese children, as defined by WAZ, WHZ and BAZ, increased from $0.1 \%$ to $1.4 \%$, from $0.6 \%$ to $2.5 \%$ and from $0.6 \%$ to $2 \cdot 6 \%$, respectively, between 1993 and 2012 (Fig. 1). In Matlab, the proportions of overweight and obese using the same criteria increased from $0.3 \%$ to $0.8 \%$, from $0.8 \%$ to 
(a)

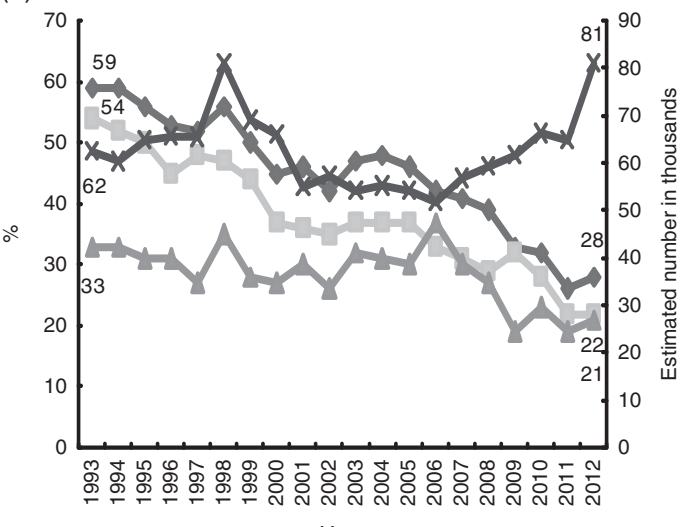

(c)

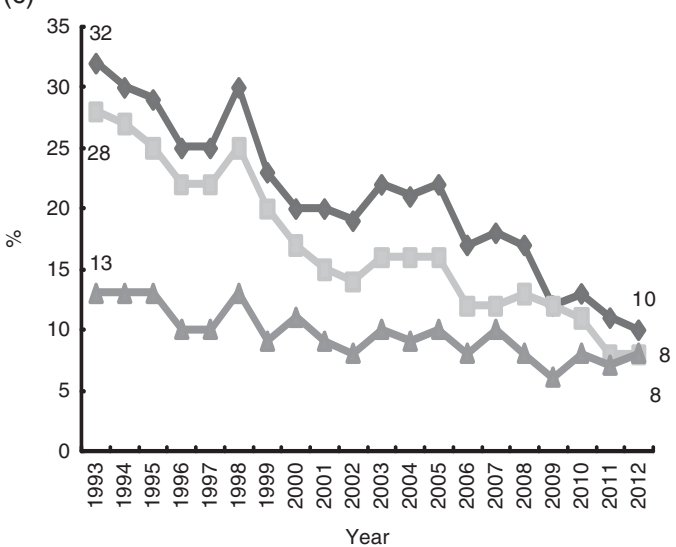

(e)

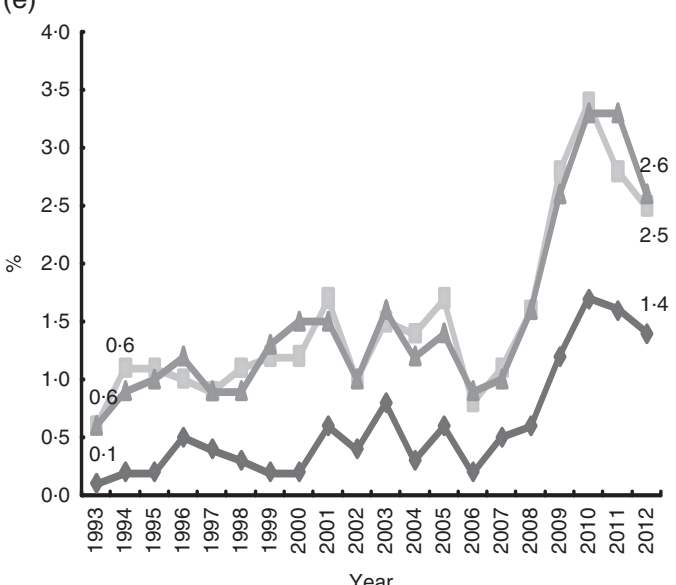

(b)

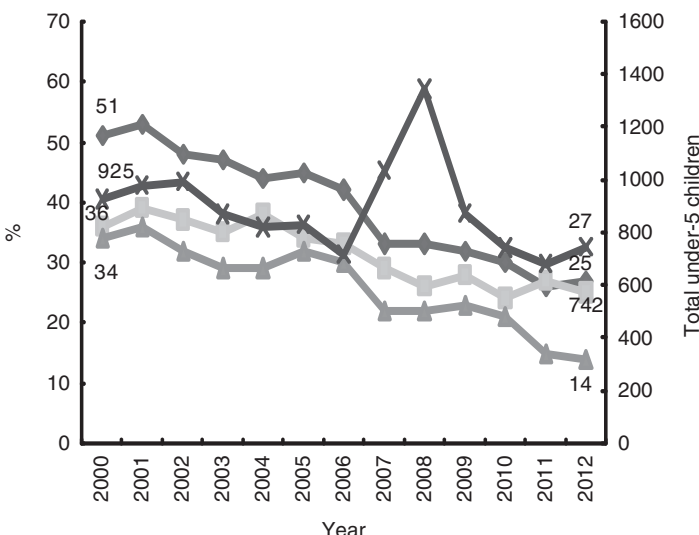

(d)

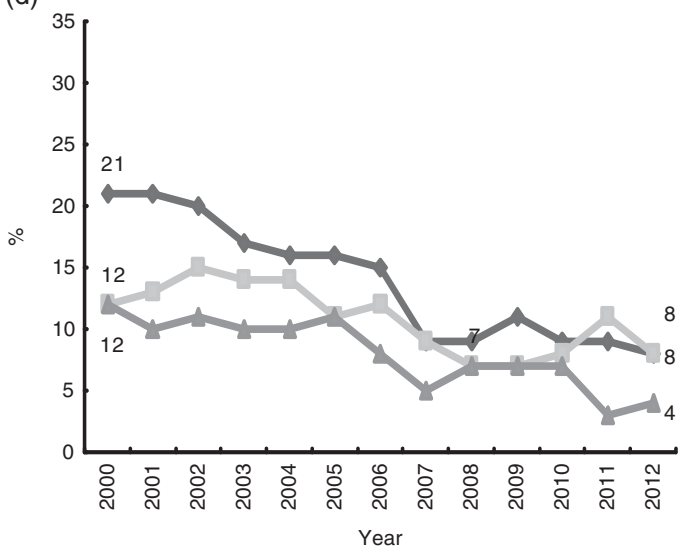

(f)

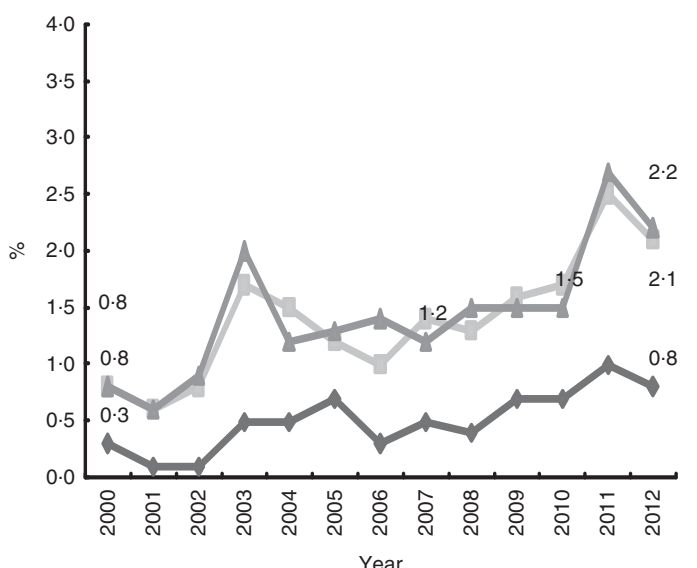

Fig. 1 Changing trend of malnutrition among under-5 children in (a, c, e) Dhaka (urban; 1993-2012) and (b, d, f) Matlab (rural; 2000-2012), Bangladesh: (a, b) malnutrition (- underweight (WAZ <-2.00); - , stunting (HAZ <-2.00); - , wasting

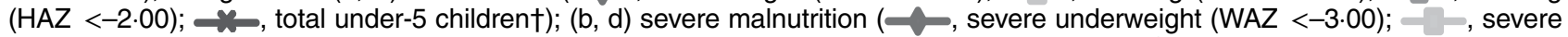
stunting (HAZ <-3.00); $\quad$, severe wasting (HAZ <-3.00)); (e, f) overweight and obese ( - WAZ >+2.00; - , WHZ > $+2.00 ;-, B Z>+2.00) ; X^{2}$ test for trend $P<0.001$ for all indicators. †Estimated number was calculated as total number of under-5 children enrolled annually multiplied by 25 for 1993-1995 and by 50 for 1996-2012 (WAZ, weight-for-age Z-score; HAZ, height-for-age Z-score; WHZ, weight-for-height Z-score; BAZ, BMI-for-age Z-score)

$2 \cdot 1 \%$ and from $0 \cdot 8 \%$ to $2 \cdot 2 \%$, respectively, between 2000 and 2012 (Fig. 1)

In urban Dhaka Hospital, the proportion of illiterate mothers of the under- 5 children decreased from $53 \%$ in
1993 to $13 \%$ in 2012 , and paternal illiteracy decreased from $39 \%$ to $17 \%$ during the study period (Fig. 2). In Maltab, maternal and paternal illiteracy reduced from $33 \%$ to $4 \%$ and from $34 \%$ to $9 \%$, respectively, between 2000 
(a)

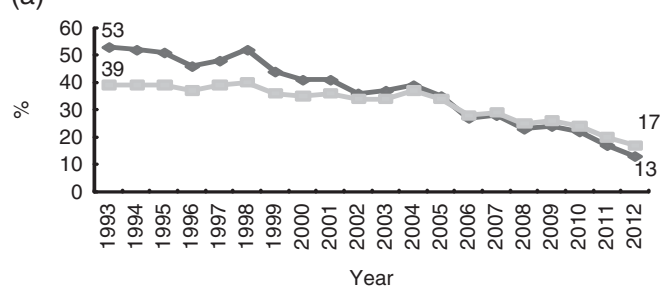

(c)

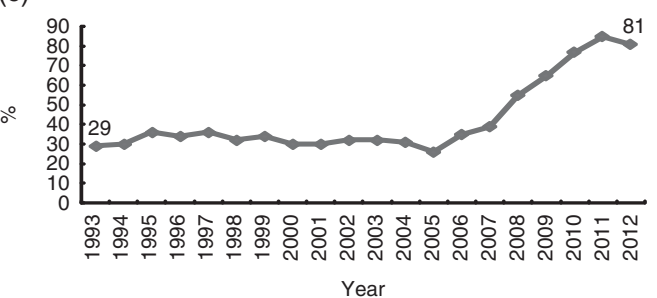

(e)

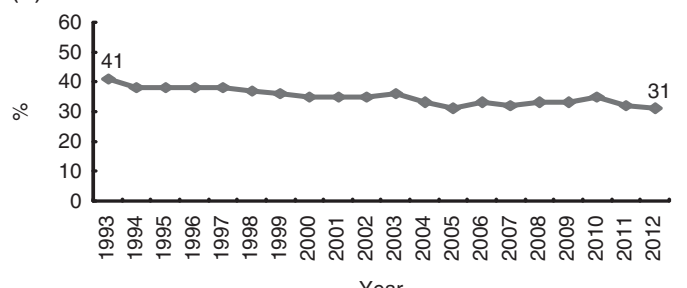

(g)

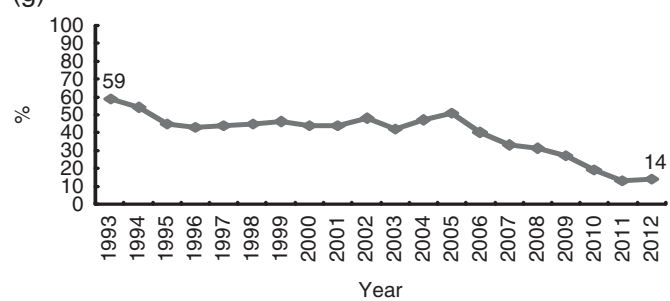

(i)

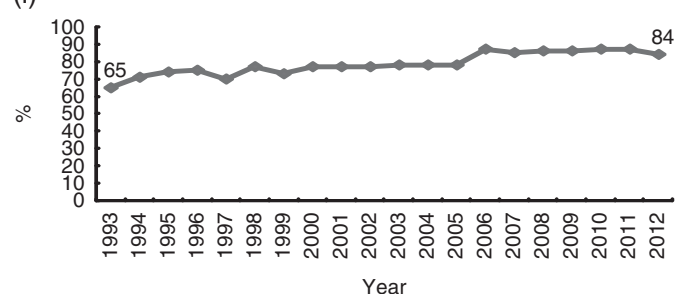

(k)

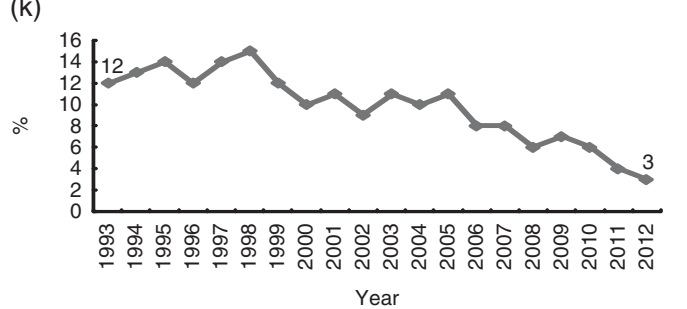

(b)

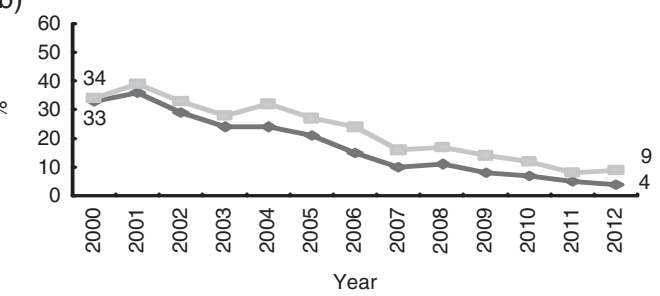

(d)

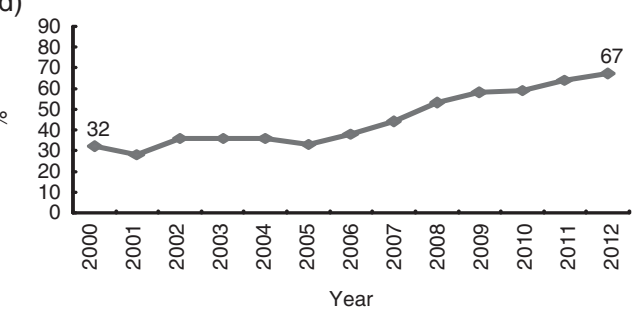

(f)

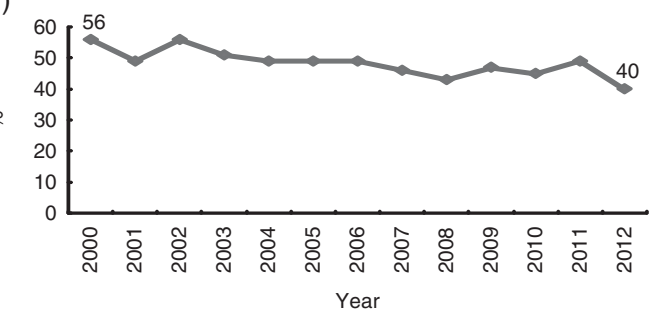

(h)

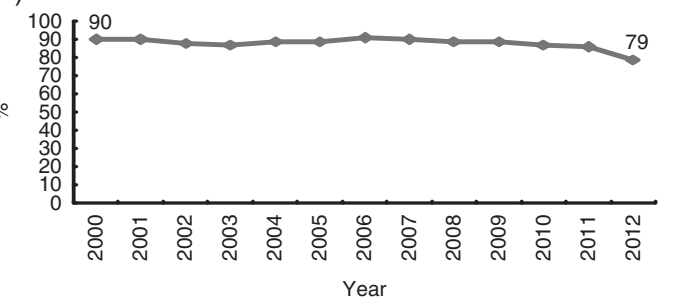

(j)

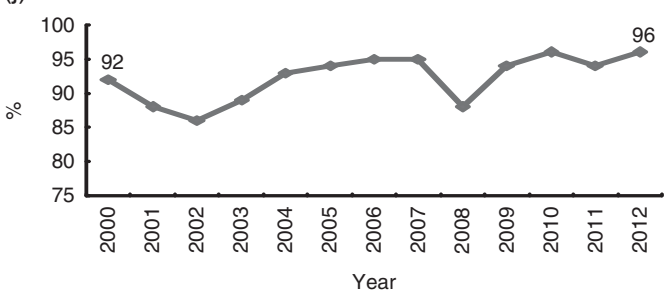

(I)

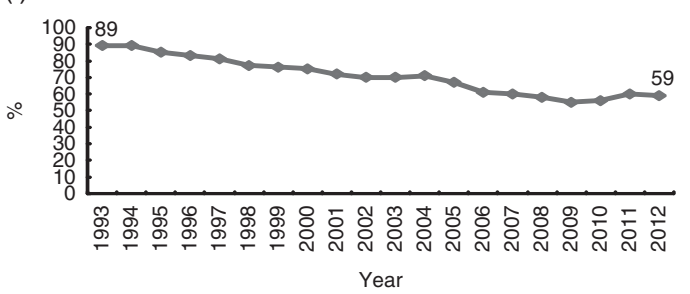

Fig. 2 Changing trend of sociodemographic indicators among under-5 children in (a, c, e, g, i, k, I) Dhaka (urban; 1993-2012) and (b, d, f, h, j) Matlab (rural; 2000-2012), Bangladesh. (a, b) illiteracy rate (- maternal illiteracy; - paternal illiteracy); (c, d) better economic status (monthly family income greater than \$US 100); (e, f) family size (more than five members); (g, h) use of nonsanitary toilet; (i, j) measles immunization (among children $\geq 9$ months old); (k) slum residence; (I) drinking untreated water; $x^{2}$ test for trend $P<0.001$ for all indicators 
and 2012 (Fig. 2). In 1993, only 29\% of the children's families in Dhaka had a monthly income greater than \$US 100, which increased to $81 \%$ in 2012. In Matlab, $32 \%$ of the children's families had monthly income greater than \$US 100 in 2000 which increased to $67 \%$ in 2012 (Fig. 2). The proportions of households with more than five members decreased in both urban (from $41 \%$ to $31 \%$ ) and rural areas (from $56 \%$ to $40 \%$ ) during the respective study periods. Significant increase in measles immunization coverage (among children $\geq 9$ months old) was observed in both study areas. The proportion of urban households using a non-sanitary toilet decreased from $59 \%$ in 1993 to $14 \%$ in 2012; among households in the rural area, this proportion decreased from $90 \%$ to $79 \%$. During the study period, the urban area observed significant reductions in the proportion of slum dwellers and the proportion of families drinking untreated water (Fig. 2).

In the urban area in 1993, underweight was significantly positively associated with children aged 12 months and older, maternal and paternal illiteracy, slum residence, all SES categories (defined by wealth quintile and considering rich as the reference category) and the use of untreated drinking-water. In 2002, such positive associations were only found for children aged 12 months and older, paternal illiteracy and all SES categories. In 2012, underweight was positively associated with child's age 24-59 months, maternal illiteracy and poor SES in the urban area (Table 2).

Stunting was noted beyond infancy in both study areas (Tables 2 and 3). Among children from the urban area, in 1993 stunting had a positive association with maternal and paternal illiteracy, slum residence, lower monthly family income, all SES categories and use of untreated drinking-water and a negative association with female sex; but in 2002, the association of stunting with child's age 12-23 months, female child, maternal and paternal illiteracy, slum residence, upper middle SES and drinking untreated water dropped from the multivariate analysis model. Findings in 2012 were almost the same as those in 2002, except that maternal illiteracy and all SES categories reappeared with positive association (Table 2 ).

In the urban area in 1993, the factors that had a significant positive association with wasting included child's age 12-23 months, maternal illiteracy, larger family size (more than five members), slum residence, lower monthly income (\$US 100 or less), lower middle and poor SES and drinking untreated water. Child's age 12 months and above, paternal illiteracy and middle, lower middle and poor SES had significantly positive associations with wasting in 2002; but, in 2012, only child's age 24-59 months and maternal illiteracy had a positive association with wasting (Table 2).

The changing predictors for childhood malnutrition (underweight, stunting and wasting) in rural Matlab were mostly similar with few exceptions, as described in Table 3 .

\section{Discussion}

Substantial improvements in nutritional status (reduced undernutrition) and increasing overweight and obesity have been observed globally over the last two decades and similar trends have also been reported from Bangladesh ${ }^{(2,4,5)}$, which strengthen our present findings. Simultaneous changes have also been observed in the risk factors for malnutrition $^{(2,15,16)}$. We found a high baseline prevalence for stunting and underweight in Dhaka, which might be due to the longer period of observation in Dhaka (20 years, 1993-2012) as compared with Matlab (13 years, 2000-2012).

In our analysis, we noted significant reductions in childhood malnutrition (undernutrition); however, the rates remain high and fall behind the target of Millennium Development Goals 1 and $4^{(1)}$. However, expected sociodemographic differences between urban and rural Bangladesh might have influenced the changing trends at different time points. Understanding potential risk factors and their appropriate response may have greater impact. Our observation of increasing childhood overweight and obesity is similar to that reported earlier ${ }^{(6-8)}$. The combination of undernutrition and overweight and obesity is a growing burden in many developing countries including Bangladesh, which is indicative of a shifting of childhood malnutrition.

Several factors might explain the reduction in malnutrition observed in our study. For example, according to the Word Bank, the poverty headcount ratio at the national poverty line of Bangladesh (percentage of the population) was $57 \%$ in 1992 and reduced gradually to $32 \%$ in $2010^{(17,18)}$. In our analysis, significant reductions in the proportion of malnourished children belonging to the upper middle and middle SES quintiles were observed over the study period ${ }^{(16)}$. This was a risk factor in 1993 and 2002, but not in 2012. Over this period families have likely benefited from microcredit programmes that were introduced to create substantial opportunities for selfemployment, liberating poor families and especially women (who are the main beneficiaries) from the clutches of poverty by bringing the poor into income streams ${ }^{(19)}$. Increased literacy rate, particularly of girls, is a major achievement of recent years in Bangladesh, which has resulted from development programmes of the Government of Bangladesh and non-government organizations ${ }^{(20,21)}$. Maternal illiteracy among malnourished children, especially in the urban area, remained a risk factor in the present study, signifying the importance of education for better child care including feeding practices ${ }^{(22)}$; at the same time, women who are illiterate are less able to increase their knowledge/acquire specific information and are also likely to have a lower income when they are employed. Earlier, maternal illiteracy was significantly associated with malnutrition at the rural Matlab site but that did not persist in 2012. The other factors that may have contributed to the changes reported here 
include improved knowledge about childhood malnutrition, better maternal and childhood feeding practices including exclusive breast-feeding of infants and young children, and high immunization coverage ${ }^{(23-28)}$. Like those in highincome countries, children in low- and middle-income countries consume foods that contain high amounts of fat, sugar and salt, with high energy density but lower micronutrient content; although these foods tend to be cheaper, they are low in nutrient quality ${ }^{(8)}$. In addition, unplanned urbanization with reduced open spaces in the urban areas and less outdoor exposure leads to reduced physical activity. Together, both of these factors result in a sharp increase in childhood overweight and obesity ${ }^{(6-8,29)}$. However, in our study we lacked data on dietary habits and physical activities to examine their role in our observed results as reported elsewhere ${ }^{(30)}$.

Expectedly, risk for malnutrition was greater beyond infancy, which might be an effect of less breast-feeding among older children, as breast-feeding protects children from malnutrition ${ }^{(31-33)}$. However, in late infancy, when children start to receive complementary foods, improper and inadequate feeding with a lack of dietary balance makes them vulnerable and they become malnourished ${ }^{(34)}$. A few studies have reported that female children are at higher risk $^{(35)}$, which was also observed in the early 1990s in the present study but did not remain so in 2012. We do not have a ready explanation and we did not determine the underlying social predictors; however, mass campaigning against gender discrepancy with overall increased awareness might potentially have played a role ${ }^{(36,37)}$.

Over the period, remarkable improvement occurred in the use of sanitary toilets ${ }^{(38,39)}$. Proper disposal of faecal matter reduces faecal contamination of water and food, and ultimately helps in reducing the transmission of enteric infections including diarrhoeal disease ${ }^{(40)}$. In the early 1990s, drinking untreated (non-boiled) water was a potential predictor of malnutrition in urban areas, which gradually disappeared in the year 2000 and persisted onward. Increased awareness about the benefits of drinking boiled water as a part of healthy lifestyle practices has substantial impact on reducing childhood mortality and morbidity ${ }^{(40)}$. On the other hand, in rural areas, tubewells are used as a safe source of drinking-water and thus this variable was not included in the model.

Food security is directly related to malnutrition. There has been much improvement in food security although it is still under great debate ${ }^{(41-43)}$. Bangladesh has achieved significant improvement in the production of staple foods ${ }^{(44)}$; to improve food security nationally, its sustainability is now of a great concern ${ }^{(42,45)}$. Natural disasters like heavy monsoons, draught, flooding, cyclones and river erosion often make inhabitants food insecure when merged with unemployment ${ }^{(46)}$. All of these factors contribute significantly to the existing high burden of malnutrition in Bangladesh and have been reported by several studies ${ }^{(42,46)}$. However, due to the lack of relevant 
Table 3 Changing risk factors for malnutrition among under-5 children in Matlab (rural; 2002-2012), Bangladesh

\begin{tabular}{|c|c|c|c|c|c|c|c|c|c|c|c|c|}
\hline \multirow{3}{*}{$\begin{array}{l}\text { Sociodemographic } \\
\text { characteristics }\end{array}$} & \multicolumn{4}{|c|}{ Underweight } & \multicolumn{4}{|c|}{ Stunting } & \multicolumn{4}{|c|}{ Wasting } \\
\hline & \multicolumn{2}{|r|}{2002} & \multicolumn{2}{|r|}{2012} & \multicolumn{2}{|r|}{2002} & \multicolumn{2}{|r|}{2012} & \multicolumn{2}{|r|}{2002} & \multicolumn{2}{|r|}{2012} \\
\hline & aOR & $95 \% \mathrm{Cl}$ & $\mathrm{aOR}$ & $95 \% \mathrm{Cl}$ & aOR & $95 \% \mathrm{Cl}$ & aOR & $95 \% \mathrm{Cl}$ & aOR & $95 \% \mathrm{Cl}$ & $\mathrm{aOR}$ & $95 \% \mathrm{Cl}$ \\
\hline \multicolumn{13}{|l|}{ Child's age } \\
\hline $12-23$ months & 1.51 & $1 \cdot 11,2 \cdot 03^{*}$ & 1.59 & $1 \cdot 10,2 \cdot 37^{*}$ & 2.44 & $1 \cdot 78,3 \cdot 34^{*}$ & 1.68 & $1 \cdot 14,2 \cdot 47^{\star}$ & 1.38 & $1 \cdot 01,1 \cdot 89^{\star}$ & 1.74 & $1 \cdot 09,2 \cdot 84^{*}$ \\
\hline 24-59 months & 2.07 & $1.43,2.94^{*}$ & $2 \cdot 36$ & $1.45,3 \cdot 88^{*}$ & $2 \cdot 28$ & $1.58,3 \cdot 26^{*}$ & $2 \cdot 13$ & $1.29,3.49^{*}$ & 1.41 & $0.98,2.03$ & 1.69 & $0.90,3.19$ \\
\hline Female & 0.92 & $0 \cdot 71,1 \cdot 24$ & 1.00 & $0.70,1.42$ & $1 \cdot 10$ & $0.83,1.48$ & $1 \cdot 17$ & $0.82,1.68$ & 1.07 & $0.81,1.44$ & $1 \cdot 12$ & $0.72,1 \cdot 77$ \\
\hline Maternal illiteracy & 1.39 & $0.98,2.02$ & 1.33 & $0.59,3.04$ & 1.25 & $0.88,1 \cdot 82$ & 0.80 & $0.34,1.91$ & 1.35 & $0.94,1.96$ & 1.35 & $0.51,3.60$ \\
\hline Paternal illiteracy & 1.37 & $0.96,1.96$ & 1.51 & $0.82,2.82$ & $1 \cdot 33$ & $0.94,1.95$ & $1 \cdot 87$ & $0.99,3.51$ & $1 \cdot 15$ & $0.79,1.63$ & 1.06 & $0.49,2.33$ \\
\hline $\begin{array}{l}\text { Family size (greater than } \\
\text { mean; > 5) }\end{array}$ & 0.92 & $0.70,1.22$ & 0.91 & $0.63,1.32$ & 1.05 & $0.78,1.40$ & 0.91 & $0.63,1.32$ & 1.06 & $0.79,1.42$ & 0.96 & $0.59,1.54$ \\
\hline $\begin{array}{l}\text { Monthly family income } \\
\leq \$ \text { US } 100\end{array}$ & $1 \cdot 30$ & $0.93,1.81$ & 0.99 & $0.65,1.51$ & $1 \cdot 39$ & $0.97,1.95$ & 1.09 & $0.71,1.61$ & $1 \cdot 18$ & $0.82,1.69$ & 0.90 & $0.53,1.57$ \\
\hline \multicolumn{13}{|l|}{ Wealth quintile } \\
\hline Upper middle & 1.25 & $0.74,2.12$ & $2 \cdot 31$ & $1.45,3.69^{*}$ & 0.66 & $0.36,1 \cdot 18$ & 1.32 & $0 \cdot 82,2 \cdot 11$ & 1.47 & $0.83,2.61$ & 1.88 & $1.01,3.51^{*}$ \\
\hline Middle & 1.62 & $1.03,2.55^{\star}$ & $2 \cdot 01$ & $1 \cdot 18,3.42^{\star}$ & 1.23 & $0.77,1.99$ & 1.69 & $1.01,2 \cdot 85^{\star}$ & 1.47 & $0.89,2.43$ & 2.83 & $1.46,5.45^{\star}$ \\
\hline Lower middle & 2.52 & $1.60,3.99^{*}$ & $2 \cdot 60$ & $1 \cdot 50,4.93^{*}$ & $1 \cdot 78$ & $1 \cdot 12,2 \cdot 87^{*}$ & 1.78 & $1.03,3.07^{\star}$ & 1.87 & $1.13,3.09$ & 1.98 & $0 \cdot 96,4 \cdot 11$ \\
\hline Poor & 2.09 & $1.24,3.51^{*}$ & 4.70 & $1.99,11.09^{*}$ & 1.42 & $0.83,2.44$ & 3.59 & $1.53,8.40^{\star}$ & 1.85 & $1.05,3.24$ & 8.92 & $3 \cdot 44,23 \cdot 07^{*}$ \\
\hline
\end{tabular}

aOR, adjusted odds ratio.

Dependent variable: underweight $=1$, stunted $=1$, wasted $=1$ and well-nourished $=0$ for each point (year) of observation.

Reference categories: child's age 0-11 months; male sex; maternal and paternal literacy; family size less than or equal to the mean; monthly income $>$ \$US 100; wealth quintile $=$ rich.

${ }^{\star} P<0.05$.

information, we could not determine these as underlying predictors except for slum dwelling and poor SES of families who are constantly facing food insecurity.

Several nutritional interventions such as supplementation with fortified food, micronutrient powder distribution, home gardening, Food and Cash programmes etc. by the Government and non-governmental organizations in both urban and rural areas of Bangladesh, along with easy and non-conditional soft loans, greater childhood immunization coverage and self-employment generation, might have contributed in reducing malnutrition ${ }^{(47-49)}$. Primary health care at grassroots level through community clinics as well as strengthening of the community health-care networks is another initiative by the Government of Bangladesh. The services include antenatal check-ups, safe delivery, early resuscitation of newborns, exclusive breastfeeding and introduction of appropriate complementary foods in a timely manner; all have reduced maternal and child death rates as well as morbidities, again impacting on the reduction of malnutrition.

\section{Limitations}

The study children included in the DDSS presented with diarrhoea, which is a known risk factor for adverse nutritional status including malnutrition ${ }^{(3,50)}$. The likelihood of infectious diseases is higher in malnourished children, including more severe diarrhoea, and thus the children in our study may not be truly representative of the general population. Moreover, repeated or multiple measurements on each child during the study period to determine nutritional consequences were not determined due to lack of a DDSS in the catchment population. icddr,b hospitals provide cost-free treatment to all individuals irrespective of their SES. This, along with systematic collection of data and large sample size, were among the strengths of our analysis.

\section{Conclusion}

A significant improvement in childhood nutritional status has been observed in over the past two decades in both urban and rural areas in Bangladesh. However, the study also identified malnutrition as an enduring problem. Significant increasing trends for overweight and obesity were also observed, which indicates a shifting of childhood malnutrition. Finally, we have identified changes in risk factors that may prove useful to the Government of Bangladesh and non-governmental organizations in developing their policies and programmes for effectively addressing the public health threat of childhood malnutrition.

\section{Acknowledgements}

Financial support: Hospital surveillance was funded by icddr,b and the Government of the People's Republic of Bangladesh through IHP-HNPRP. icddr,b acknowledges with gratitude the commitment of the Government of the People's Republic of Bangladesh to icddr,b's research efforts. icddr,b also gratefully acknowledges the following donors who provided unrestricted support to its research efforts during the project's life: the Australian Agency for International Development (AusAID); the Government of the People's Republic of Bangladesh; the Canadian International Development Agency (CIDA); the Embassy of the Kingdom of the Netherlands (EKN); the Swedish 
International Development Cooperation Agency (Sida); the Swiss Agency for Development and Cooperation (SDC); and the Department for International Development, UK (DFID). The sponsors of the study had no role in study design, data collection, data analysis, data interpretation, or writing of the report. Conflict of interest: None. Authorship: S.K.D., A.A.M. and A.S.G.F. designed the research (project conception, development of overall research plan, study oversight). M.A.M., M.A.S. and A.S.G.F. conducted the research (hands-on conduct of the experiments and data collection). M.A.M. and A.S.G.F. provided essential materials (databases). M.A.M., S.K.D., J.D., M.A.S. and A.A.M. analysed the data or performed statistical analyses. S.K.D., M.J.C., J.D., T.A. and A.S.G.F. wrote the paper (only authors who made a major contribution). T.A. and A.S.G.F. had primary responsibility for final content. All authors reviewed the paper. S.K.D. had full access to all the data in the study and had final responsibility for the decision to submit for publication. Ethics of human subject participation: Verbal consent was taken from the parents or the attending caregivers of each child at the time of enrolment. icddr,b's DDSS is a routine ongoing activity of the Dhaka Hospital and Matlab Hospital, which has the approval of the institutional Research Review Committee) and Ethical Review Committee.

\section{References}

1. Statistics Division, Department of Economic and Social Affairs, United Nations (2012) Millennium Development Goals: 2012 Progress Chart. http://www.un.org/millen niumgoals/pdf/2012_Progress_E.pdf (accessed January 2015).

2. Bhutta ZA, Ahmed T, Black RE et al. (2008) What works? Interventions for maternal and child undernutrition and survival. Lancet 371, 417-440.

3. Brown KH (2003) Diarrhea and malnutrition. J Nutr 133, issue $1,328 \mathrm{~S}-332 \mathrm{~S}$.

4. De Onis M, Blossner M \& Borghi E (2012) Prevalence and trends of stunting among pre-school children, 1990-2020. Public Health Nutr 15, 142-148.

5. De Onis M, Blossner M, Borghi E et al. (2004) Estimates of global prevalence of childhood underweight in 1990 and 2015. JAMA 291, 2600-2606.

6. De Onis M, Blossner M \& Borghi E (2010) Global prevalence and trends of overweight and obesity among preschool children. Am J Clin Nutr 92, 1257-1264.

7. Wang Y \& Lim H (2012) The global childhood obesity epidemic and the association between socio-economic status and childhood obesity. Int Rev Psychiatry 24, 176-188.

8. World Health Organization (2013) Obesity and Overweight. Fact Sheet no. 311. Geneva: WHO.

9. National Institute of Population Research and Training, Mitra and Associates \& ORC Macro (2001) Bangladesh Demographic and Health Survey 1999-2000. Dhaka and Calverton, MD: NIPORT, Mitra and Associates, and ORC Macro; available at http://dhsprogram.com/pubs/pdf/FR119/FR119.pdf.

10. National Institute of Population Research and Training, Mitra and Associates \& ICF International (2009) Bangladesh Demographic and Health Survey 2007. Dhaka and Calverton, MD: NIPORT, Mitra and Associates, and Macro International; available at http://www.measuredhs.com/ pubs/pdf/FR207/FR207\%5BApril-10-2009\%5D.pdf
11. National Institute of Population Research and Training, Mitra and Associates \& ICF International (2013) Bangladesh Demographic and Health Survey 2011. Dhaka and Calverton, MD: NIPORT, Mitra and Associates, and Macro International; available at http://www.measuredhs.com/ pubs/pdf/FR265/FR265.pdf

12. Das SK, Chisti MZ, Huq S et al. (2013) Etiology of diarrhea among severely malnourished infants and young children: observation of urban-rural differences over one decade in Bangladesh. Food Nutr Sci 4, 233-239.

13. Nahar B, Hamadani JD, Ahmed T et al. (2009) Effects of psychosocial stimulation on growth and development of severely malnourished children in a nutrition unit in Bangladesh. Eur J Clin Nutr 63, 725-731.

14. Onyango AW \& De Onis M (2008) Traning Course on Child Growth Assessment: WHO Child Growth Standards. Geneva: WHO

15. Nahar B, Ahmed T, Brown KH et al. (2010) Risk factors associated with severe underweight among young children reporting to a diarrhoea treatment facility in Bangladesh. J Health Popul Nutr 28, 476-483.

16. Chisti MJ, Hossain MI, Malek MA et al. (2007) Characteristics of severely malnourished under-five children hospitalized with diarrhoea, and their policy implications. Acta Paediatr 96, 693-696.

17. The World Bank (2010) Bangladesh, World Development Indicators. http://data.worldbank.org/country/bangladesh (assessed June 2013).

18. Index Mundi (2011) Bangladesh - GDP per capita, GDP per capita (current US\$). http://www.indexmundi.com/facts/ bangladesh/gdp-per-capita (accessed April 2013).

19. Ahshanullah M, Karim R \& Haq E (2011) Reaching the poor: microcredit experience in Bangladesh. ASA Univ Rev 5, issue 2, 11-31; available at https://www.scribd.com/doc/ .../Major-Policy-Issues-of-Bangladesh

20. UNICEF Bangladesh (2009) Quality Primary Education in Bangladesh. Dhaka: UNICEF Bangladesh; available at http:// www.unicef.org/bangladesh/Quality_Primary_Education(1). pdf

21. General Economics Division, Planning Commission, Government of the People's Republic of Bangladesh \& UNDP Bangladesh (2009) A Situation Analysis Report on Education (MDG 2). Bangladesh. A Baseline for Needs Assessment and Costing. http://planipolis.iiep.unesco.org/upload/Bangladesh/ Bangladesh_MDG_Situation_analysis.pdf (January 2015).

22. Meshram II, Kodavanti MR, Chitty GR et al. (2013) Influence of feeding practices and associated factors on the nutritional status of infants in rural areas of Madhya Pradesh State, India. Asia Pac J Public Health (Epublication ahead of print version)

23. Benakappa AD \& Shivamurthy P (2012) Beliefs regarding diet during childhood illness. Indian J Community Med 37, 20-24.

24. Patel A, Badhoniya N, Khadse S et al. (2010) Infant and young child feeding indicators and determinants of poor feeding practices in India: secondary data analysis of National Family Health Survey 2005-06. Food Nutr Bull 31, 314-333.

25. Mihrshahi S, Kabir I, Roy SK et al. (2010) Determinants of infant and young child feeding practices in Bangladesh: secondary data analysis of Demographic and Health Survey 2004. Food Nutr Bull 31, 295-313.

26. Faruque AS, Ahmed AM, Ahmed T et al. (2008) Nutrition: basis for healthy children and mothers in Bangladesh. J Health Popul Nutr 26, 325-339.

27. General Economics Division, Planning Commission, Government of the People's Republic of Bangladesh \& UNDP Bangladesh (2009) A Situation Analysis Report on Health (MDG 4, 5 and 6). Bangladesh. A Baseline for Needs Assessment and Costing. http://s3.amazonaws.com/ 
zanran_storage/www.undp.org.bd/ContentPages/44320590. pdf (accessed January 2015).

28. Cruz Agudo Y, Jones AD, Berti PR et al. (2010) Breastfeeding, complimentary feeding practices and childhood malnutrition in the Bolivian Andes. Arch Latinoam Nutr 60 , 7-14.

29. Plachta-Danielzik S, Kehden B, Landsberg B et al. (2012) Attributable risks for childhood overweight: evidence for limited effectiveness of prevention. Pediatrics 130 , e865-e871.

30. Bloem MW, de Pee S, Hop le T et al. (2013) Key strategies to further reduce stunting in Southeast Asia: lessons from the ASEAN countries workshop. Food Nutr Bull 34, 2 Suppl., S8-S16.

31. Dong GH, Qian ZM, Liu MM et al. (2013) Breastfeeding as a modifier of the respiratory effects of air pollution in children. Epidemiology 24, 387-394.

32. Camurdan MO, Camurdan AD, Polat S et al. (2011) Growth patterns of large, small, and appropriate for gestational age infants: impacts of long-term breastfeeding: a retrospective cohort study. J Pediatr Endocrinol Metab 24, 463-468.

33. Dey SK, Chisti MJ, Das SK et al. (2013) Characteristics of diarrheal illnesses in non-breast fed infants attending a large urban diarrheal disease hospital in Bangladesh. PLoS One 8, e58228.

34. Kramer MS \& Kakuma R (2012) Optimal duration of exclusive breastfeeding. Cochrane Database Syst Rev $\mathbf{8}$, CD003517.

35. Choudhury KK, Hanifi MA, Rasheed S et al. (2000) Gender inequality and severe malnutrition among children in a remote rural area of Bangladesh. J Health Popul Nutr 18, 123-130.

36. Mahmud W (2008) Social development in Bangladesh: pathways, surprises and challenges. Indian J Hum Dev 2 , 79-92.

37. Hubbard G (2013) Fighting Malnutrition in Bangladesh with Education. Dhaka: UNICEF Bangladesh.

38. Water Sanitation Programme, World Bank (2011) Mapping of Hard to Reach Areas of Bangladesh, Water and Sanitation Program. Dhaka: World Bank Bangladesh.

39. Zheng Y, Hakim SAI, Nahar Q et al. (2013) Sanitation coverage in Bangladesh since the millennium: consistency matters. J Water Sanit Hyg Dev 3, 240-251.

40. Thapar N \& Sanderson IR (2004) Diarrhoea in children: an interface between developing and developed countries. Lancet 363, 641-653.

41. Ministry of Food and Disaster Management, Government of the People's Republic of Bangladesh \& World Food Programme Bangladesh (2005) Report of the National
Workshop on Food Security in Bangladesh, 19-20 October 2005. http://documents.wfp.org/stellent/groups/public/ documents/liaison_offices/wfp121955.pdf (accessed January 2015).

42. FPMU, Food Division, Ministry of Food and Disaster Management \& Government of the People's Republic of Bangladesh (2012) National Food Policy Plan of Action and Country Investment Plan. Monitoring Report 2012. Dhaka: FPMU, Food Division, Ministry of Food and Disaster Management and Government of the People's Republic of Bangladesh; available at http://www.nfpcsp.org/agridrupal/ sites/default/files/Monitoring\%20report\%202012\%20rev.pdf

43. World Food Programme-Bangladesh (2012) Bangladesh Food Security Monitoring Bulletin no. 11. Dhaka: World Food Programme-Bangladesh.

44. Begum MEA \& D'Haese L (2010) Supply and demand situations for major crops and food items in Bangladesh. J. Bangladesh Agril Univ 8, 91-102.

45. Rudolph L (2011) Increasing food security by asset transfer. Evidence of a pro-ultra-poor intervention in Bangladesh. Paper submitted to the First International Conference on International Relations and Development, Thammasat University, Bangkok, Thailand, 19-20 May 2011. http:// bangladesch.org/fileadmin/redaktion/Bilder/B_Globales_ Lernen/B3.2_Oeffentlichkeitsarbeit/Mediathek/Studien/LukasRudolph-Increasing-Food.pdf (accessed January 2015).

46. World Food Programme-Bangladesh (2008) Emergency Safety Net for Vulnerable Groups Affected by High Food Prices and Natural Disasters in Bangladesh (EMOP: 10788.0). Dhaka: World Food Programme-Bangladesh; available at http://one.wfp.org/operations/current_operations/ project_docs/107880.pdf

47. Bangladesh Bureau of Statistics \& UNICEF (2007) Child and Mother Nutrition Survey of Bangladesh, 2005. Dhaka: Bangladesh Bureau of Statistics and UNICEF; available at http://www.unicef.org/bangladesh/Child_and_Mother_ Nutrition_Survey.pdf

48. Raisul H, Kaosar A, Tina S et al. (2012) Alive \& Thrive: expanding community interventions to improve nutrition in Bangladesh. IFPRI Focus 19, Brief 10 June, 2012. http:// www.ifpri.org/sites/default/files/publications/focus19_10. pdf (accessed January 2015).

49. Ahmed T, Mahfuz M, Ireen S et al. (2012) Nutrition of children and women in Bangladesh: trends and directions for the future. J Health Popul Nutr 30, 1-11.

50. Rodriguez L, Cervantes E \& Ortiz R (2011) Malnutrition and gastrointestinal and respiratory infections in children: a public health problem. Int J Environ Res Public Health 8, 1174-1205. 